APLL Advances in Peer-Led Learning

$\begin{array}{lll}\text { Number } 1 & \text { Fall } 2021 & \text { Article } 13\end{array}$

\title{
The Story of the Weeping Tomato: A Depiction of Osmosis in
} Action

James E. Becvar

University of Texas at El Paso

jbecvar@utep.edu

\section{Recommended Citation}

Becvar, J.E. (2021). The Story of the Weeping Tomato: A Depiction of Osmosis in Action. Advances in Peer-Led Learning, 1, 155-161. Online at https://doi.org/10.54935/apll2021-01$\underline{13-155}$ 


\title{
The Story of the Weeping Tomato: A Depiction of Osmosis in Action
}

\author{
James E. Becvar \\ Department of Chemistry and Biochemistry \\ University of Texas at El Paso \\ El Paso, Texas 79968 \\ jbecvar@utep.edu
}

\begin{abstract}
The important chemical and biological phenomenon of osmosis is depicted in a sequence of photographs. Sugar placed on a cut tomato half becomes wet and then dissolves in water withdrawn from the tomato cells by the process of osmosis.
\end{abstract}

Key Words: Osmosis, Peer Leader, PLTL Workshop, Photographical Demonstration of Science, Chemistry Circus 


\section{$\underline{\text { Introduction }}$}

The Story of the Weeping Tomato provides a photographical sequence that depicts an important chemical phenomenon called osmosis. Osmosis represents the spontaneous net passage of solvent molecules from a less concentrated solution through a semi-permeable membrane into a more concentrated solution in the direction to achieve equal concentrations on both sides of the membrane. The concepts of osmosis and osmotic pressure are important topics in introductory courses in biology and chemistry.

Materials

One tomato

One teaspoon

One sharp knife

Sugar

One plate

Camera

Paper towel

Time

\section{Method}

A tomato is cut in half, both sides are tamped dry with a paper towel. On the tomato half on the left side, one teaspoon of sugar is spread. A series of photographs is taken at designated intervals.

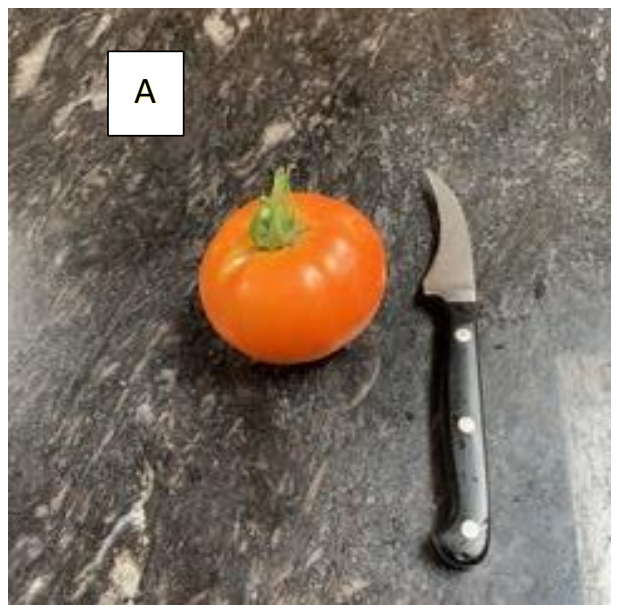

Photo $\mathrm{A}$ is Mr. Tomato on the kitchen countertop about to be cut in half. 


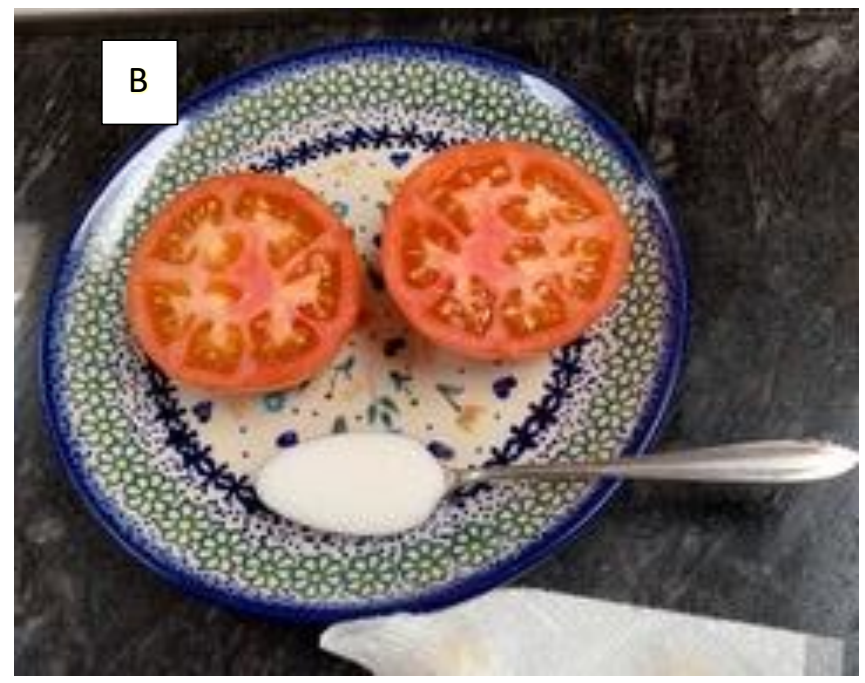

Photo B is Mr. Tomato after being cut in half. Both halves have been tamped and dried off with a paper towel and placed cut side up onto the plate in the photo. Photo B includes sugar in a teaspoon along with the 'tamped-dry' tomato halves.

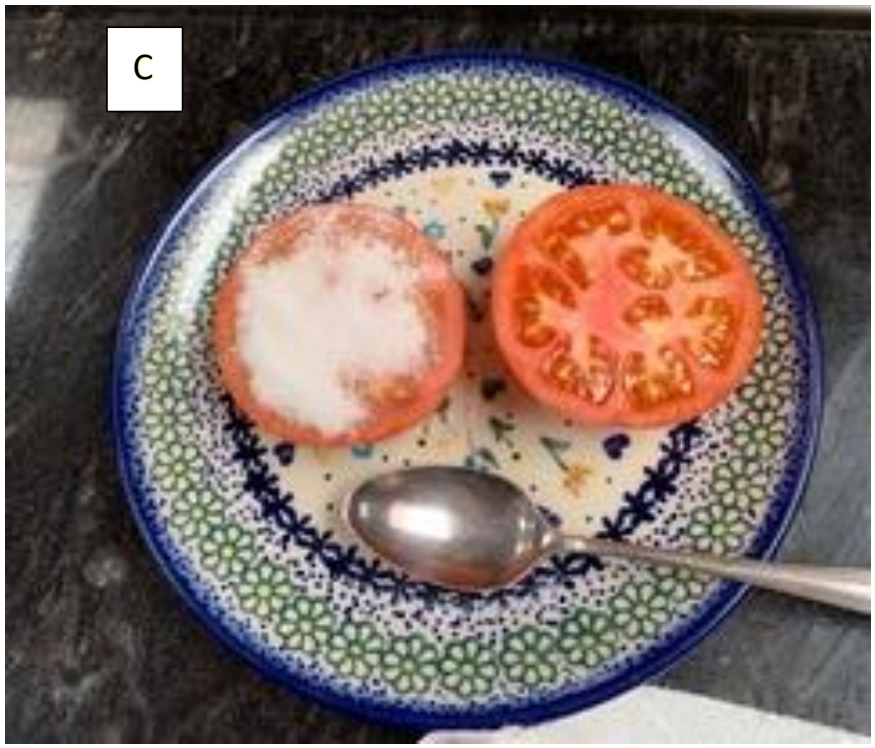

Photo $\mathbf{C}$ is a few seconds after sprinkling the spoonful of sugar as evenly as possible onto the tomato half on the left side. It is important to note that the dry sugar is opaque. 


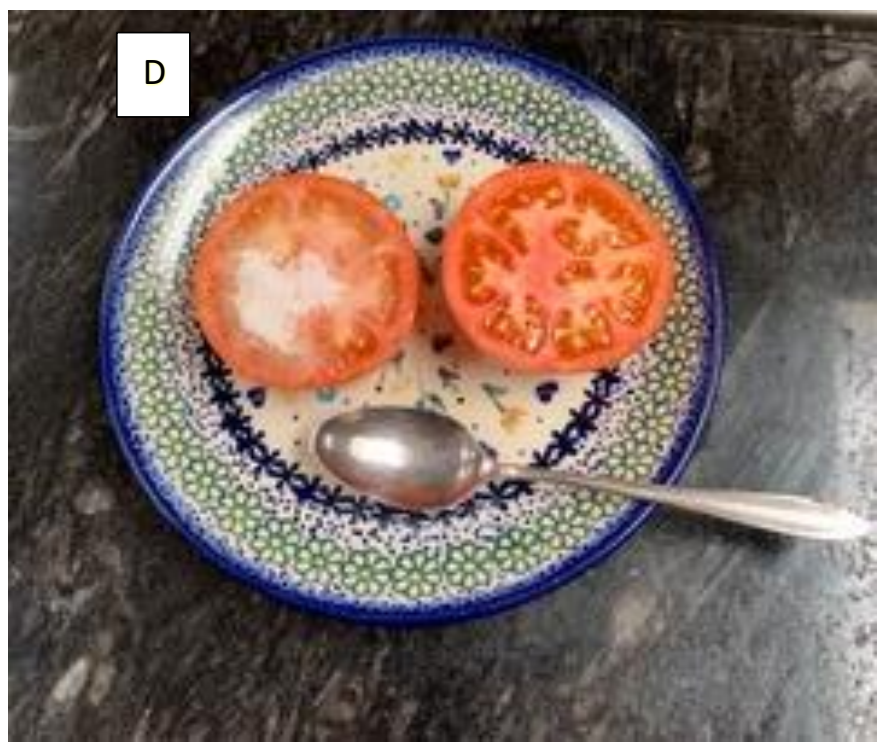

Photo D is one minute later and shows the 'wetting' of the sugar caused by the process of osmosis: the sugar layer is becoming translucent as many of the sugar granules have become wetted by water withdrawn from the tomato half by the process of osmosis.

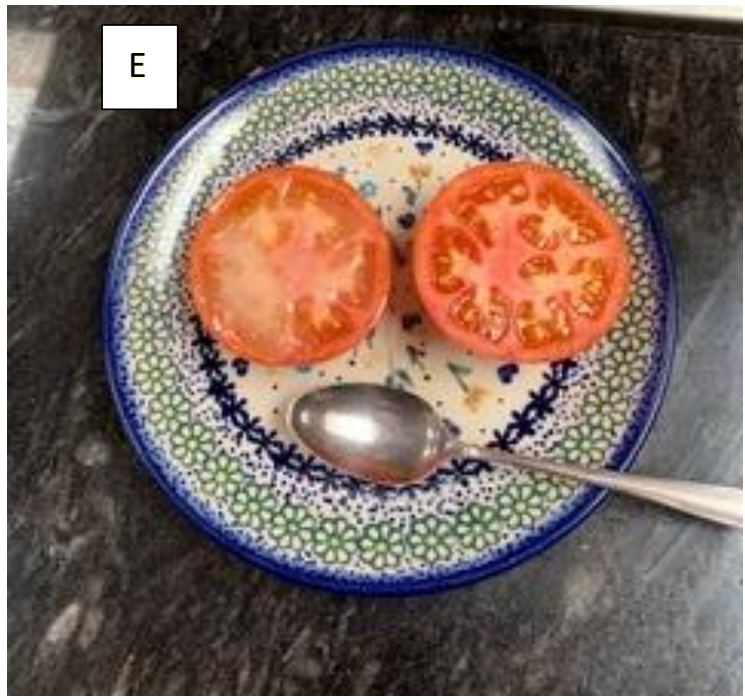

Photo $\mathbf{E}$ is taken after one additional minute showing the absence of opacity of the sugar granules because of the complete wetting of the granules withdrawn by the process of osmosis. 


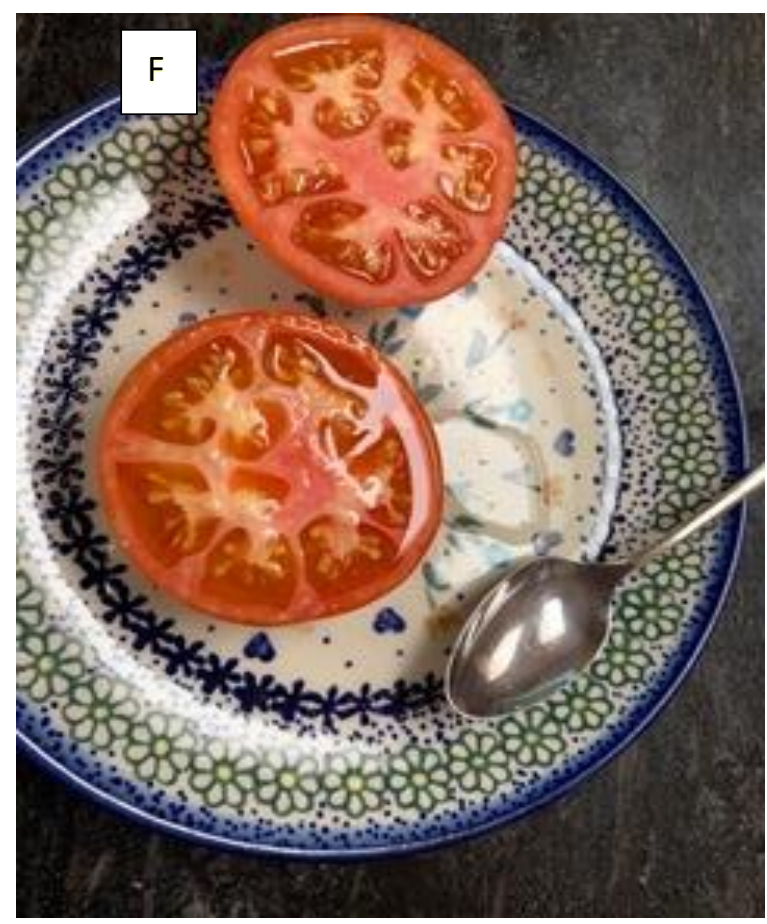

Photo $\mathbf{F}$ is after about five additional minutes: liquid water has been osmotically drawn out of the tomato half, is seen to be accumulating on the tomato half surface to which the sugar had been added and has nearly completely dissolved the sugar; the other tomato half is still 'dry.'

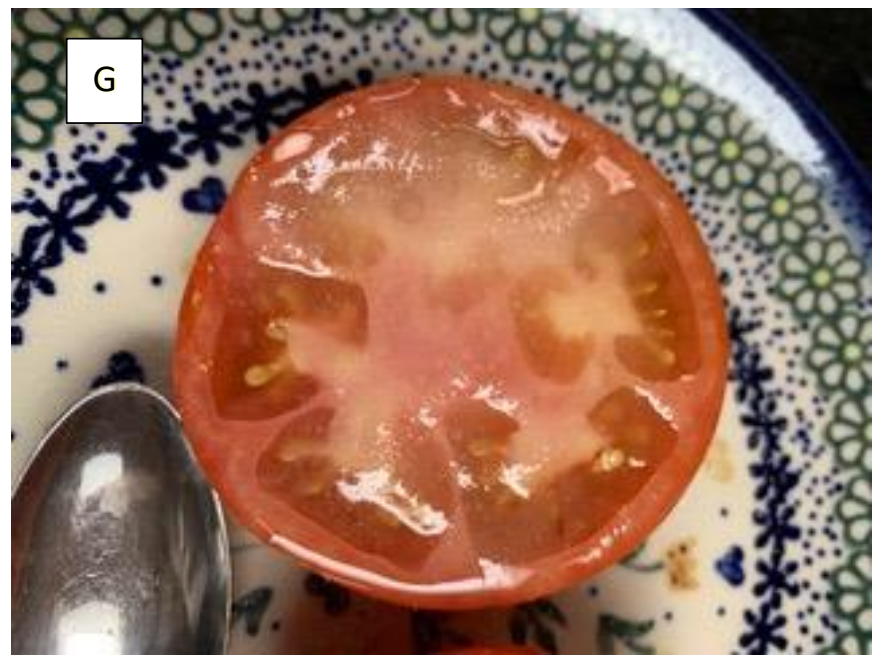

Photo $\mathbf{G}$ shows a closeup of the osmotic weeping of Mr. Tomato. 


\section{Discussion}

What is presented here is a simple demonstration of an important process of science that can be used in a Peer-Led Team Learning workshop on-line or in-person, or simply enjoyed at home. Sugar was used in this instance in order to better enjoy the final product (the would-be Photo H), but salt could also have been used. Students could also duplicate or replicate this demonstration using some other fruit or vegetable.

Peer Leaders at the University of Texas at El Paso conduct Explorations, like the Weeping Tomato Exploration, to enhance the learning of students in a peer-led Workshop (Khateeb, et al., 2006). Explorations provide real-world examples of chemical processes of a more descriptive and qualitative nature than the rather lengthy prescriptive investigations forming the basis of the usual three-clock-hour experiments in a chemistry laboratory. Students experience a sensory (usually visual) event, then grapple with what is happening chemically. One goal of "doing" the Explorations is for students to deduce a process or write a relevant balanced chemical equation rather than to perform a set of calculations, plot a graph, or conduct other data analysis.

This activity could be conducted by any child after about the age of five to help parents gain a better understanding of science. Parents, representing 'the more knowledgeable peer' (Vygotsky, 1962), could use this activity to demonstrate that science is everywhere. This dramatic demonstration of a natural phenomenon is reminiscent of the vignettes conducted during the "Chemical CirCus," a learning outreach activity performed by University of Texas at El Paso Peer Leaders in chemistry and American Chemical Society students for learners of all ages in the El Paso community (Ashmus, et al., 2007; Dadras, et al., 2000; Herrera, et al., 2009). Chemistry CirCus performances on and off campus have demonstrated that Peer Leaders and college students under supervision can and do support the learning of younger students at sponsored events.

\section{Acknowledgments}

The author sincerely thanks reviewers for their helpful suggestions for improvement and enhancement. 


\section{References}

Ashmus, R. A., Heredia, G., Avila, N., Pasillas, C., Deemer, E.M., \& Becvar, J.E. (2007). Schooling at the 'Chemistry CirCus.' 233 $3^{\text {rd }}$ ACS National Meeting, Chicago, Illinois.

Dadras, L., Casteneda, F., Chavez, C., \& Becvar, J.E. (2000). The Chemistry Circus: introducing chemical experiments to students of all ages. Division of Chemical Education, 219th American Chemical Society National Meeting, San Francisco, California.

Herrera, G. V., Miramontes, A.S. Ronquillo, L.T., Ramirez, C., Mendez, J.E., Garcia, Y.A., \& Becvar, J.E. (2009). The Chemistry CirCus: Outreach for Students of All Ages, \#373. $65^{\text {th }}$ Southwestern Regional American Chemical Society Meeting, El Paso, Texas.

Khateeb, O., Dickson, W. E., Hernandez, J., \& Becvar, J. E. (2006). Explorations: The 'Whys Have It', in 'A Decade of Peer-Led Team Learning Symposium', 232 ${ }^{\text {nd }}$ American Chemical Society National Meeting, San Francisco, California.

Vygotsky, L. S. (1962). Thought and Language. Cambridge, MA: MIT Press. 